Antony J. Puddephatt,

Lakehead University, Canada

Steven Kleinknecht,

Brescia University College, Canada

Carrie B. Sanders,

Wilfrid Laurier University, Canada

DOl: https://doi.org/10.18778/1733-8077.9.3.01

\section{Introduction to the Special Issue}

\section{Qualitative Analysis Conference 2012: Cultures of Narrative and Narratives of Culture}

\begin{abstract}
Antony J. Puddephatt is an Associate Professor in the Department of Sociology, Lakehead University, Canada. His main research interest is in the philosophy of George Herbert Mead, and its relevance for contemporary debates in social theory. He has also studied the competitive culture of amateur chess, as well as various issues facing the discipline of sociology in Canada. With Steven Kleinknecht and William Shaffir, he is the Editor of the volume Ethnographies Revisited: Constructing Theory in the Field (Routledge 2009), which centers on first-hand reflections about ethnographic "theory-work" from top qualitative researchers, including Norman Denzin, Loïc Wacquant, Harry Collins, Kathy Charmaz, Trevor Pinch, Donileen Loseke, Patricia and Peter Adler, and Laurel Richardson, among many others.

email address: apuddeph@lakeheadu.ca
\end{abstract}

Steven Kleinknecht is an Associate Professor of Sociology at Brescia University College in Canada. His research interests lie in the study of deviance, subcultures, online interaction, and cultural continuity. He has researched computer hackers and Old Order Mennonites.
With Antony Puddephatt and William Shaffir, he has coedited Ethnographies Revisited: Constructing Theory in the Field.

email address: skleinkn@uwo.ca

Carrie B. Sanders is an Associate Professor of Criminology at Wilfrid Laurier University. Her theoretical areas of interest are social constructionism, symbolic interactionism, social shaping of technology, and critical criminology. Her research interests include qualitative methodologies (specifically, the role of emotionality in the research process) and policing, with a specific interest in intelligence-led policing practices. Her ethnographic research on police information technologies and the shift toward intelligence-led policing in Canada is funded by the Social Sciences and Humanities Research Councils of Canada. Her research has appeared in journals such as Sociology, International Journal of Policing and Society, Canadian Review of Sociology, Social Science and Medicine, Qualitative Health Review, and Science and Public Policy.

email address: csanders@wlu.ca
This conference marks the $29^{\text {th }}$ year of a growing 1 tradition of qualitative research and analysis in Canada. As well as drawing several Canadian ethnographic and qualitative scholars, both junior and senior, we attract more and more international researchers each year. We have also enjoyed excellent funding support from the Social Sciences and Humanities Research Council (Canada's national funding body), as well as a number of partnering universities from across Canada (see www.qualitatives.ca for more information). This past year, we held workshops on practical considerations in qualitative research, narrative methodology, actornetwork theory, and autoethnography. We also welcomed featured speakers who discussed different issues related to qualitative research. These included Beverley Diamond on the problematic silencing and censoring of First Nations collaborators, Andrea Doucet on the concept of reflexivity, and Deborah van den Hoonaard on combining narrative inquiry and symbolic interaction in research designs. We were pleased to welcome Donileen Loseke as our keynote speaker, who gave an enlightening talk about how to study and analyze narrative patterns in social life.

The editors of the Qualitative Sociology Review (QSR) were again most gracious in permitting their journal to serve as a forum for some of the research presented at our 2012 conference. Readers may be directed to volume VIII, issue I, of the QSR for another feature in this journal, which showcased papers from our conference in the previous year. We certainly extend our thanks to the editorial team here for what is growing to be a journal for qualitative research with a truly international reputation, endorsed by the contributions of some world renowned scholars. The Qualitative Sociology Review remains committed to publishing important qualitative research from a wide range of perspectives, is completely free and open-access, and maintains solid standards of peer review. Indeed, this should be a model for other journals to follow in the growing future of electronically mediated scholarly publishing.

This special issue features two papers that are based on our keynote and featured presentations from the 2012 conference, as well as three excellent papers from the regular sessions. This issue, much like the conference, contains a strong narrative theme, considering the potential of this for building on existing qualitative traditions. We also include other papers that did not correspond to this theme but were very strong qualitative research papers and hence, excellent contributions to this issue. As usual, we received many papers for consideration, but we were only able to select these five for inclusion in the special issue.

Our first paper is based on the keynote address by Donileen Loseke, entitled "Empirically Exploring Narrative Productions of Meaning in Public Life," and asks how to best interpret and decode narrative meanings in the context of our increasingly diverse and fragmented modern society. Building on her research about stories of family violence, this paper puts forth a methodology for narrative inquiry, and uses the concepts of emotion codes and symbolic codes to think about how characters, plots, morals, and stories are interpreted by different social groups according to specific logics. The result is a truly inspiring agenda for those interested in pursuing narrative inquiry with qualitative research, but from an analytical and empirical framework, that strives to make the complex become clear rather than vice-versa. 
Our second paper is based on a featured presentation by Deborah K. van den Hoonaard, entitled "Telling the Collective Story: Symbolic Interactionism in Narrative Research." Building on her research on the contrasting experiences and stories of widows and widowers, as well as the tales from Iranian Bahá'í refugees to Canada, van den Hoonaard considers how narrative inquiry might be adopted from a specifically symbolic interactionist standpoint. She aims to take the seemingly idiosyncratic stories individuals tell, and, using sensitizing concepts and hunting for latent meanings, consider their patterning across cases, eventually "telling the collective story" of the marginalized populations she studies. This paper is as fascinating as it is emotionally gripping, providing deep insights not only into her research strategy but also the touching personal reflections of her respondents.

Third, Elizabeth Krahn has provided an informative research paper entitled "Transcending the 'Black Raven': An Autoethnographic and Intergenerational Exploration of Stalinist Oppression." Her study focused on Russian Mennonite women and their sons and daughters who lost male family members to Stalin's oppressive regime, and fled Russia in WWII to settle in Canada. Bringing together narratives from 16 individuals, she builds a collective narrative for each generation, exploring how they deal with the trauma of these past events. The narrative work they do in the present matters for how they remember and give meaning to the past, for example, emphasizing resilience during the events while downplaying emotions and weakness. But, the pain and insecurity that was not talked about in this history had damaging long-term effects, and the second generation experienced a certain emotional unavailability on the part of their mothers. Krahn argues convincingly that instead of dealing with trauma on an individual basis, these intergenerational narratives can help bring collectively experienced trauma to the surface, and allow for greater understanding and emotional healing. This paper is a true model for both the importance of autoethnographic research that is rigorously grounded in the narrative experiences of multiple others, and for the advantages and practical gains made possible by intergenerational research strategies like this one.

The fourth article, by Behrokh Nikaiin, Tam Donnelly, Nahrida Nazir, Roqaia Ahmed Dorri, Ambreen Mohammad, and Nish Petal, is entitled "Contextual Factors Influencing Breastfeeding Practices Among Arab Women in the State of Qatar." Noting the significant health benefits of breastfeeding, Nikaiin and her colleagues consider how social factors and women's knowledge of breastfeeding affect the choice to breastfeed. In-depth interviews with 32 Arab mothers provide insight into how these factors operate in the social context of Qatar. Supportive parents, husbands, healthcare professionals, and work schedules are particularly influential. In considering their findings, the authors offer suggestions for promoting breastfeeding. For instance, they argue for increased education of mothers and employers on the benefits of breastfeeding and the need for government to oversee the development and implementation of supportive workplace policies. In carefully situating women's perspectives on breastfeeding within the local context of Qatar, Nikaiin and her colleagues have developed a study that is demonstrative of how qualitative research can help inform state, cultural, and individual practices pertaining to healthcare provision and decision-making.

Finally, Rosemary Ricciardelli and Amber Gazso's piece, entitled "Investigating Threat Perception Among Correctional Officers in the Canadian Provincial Correctional System," provides an insightful analysis of the ways in which violence, or threats of violence, shape correctional officers' sense of self and self concept over time. In this account, Ricciardelli and Gazso draw attention to a social world in flux - a space where correctional officers serve as protectors to others (such as the general public and offenders), as well as to self. Through in-depth interviews with correctional officers, the researchers illuminate how threats extend beyond physical and mental victimization to one's ever evolving self concept. Finally, through their analysis, they uncover the strategies correctional officers employ to mitigate victimization and threat, such as presenting a confident and authoritative self-presentation, building positive relationships with colleagues, and maintaining respectful relationships with the prisoners.

We had a fun time working as guest editors, overseeing the development of the diverse papers that make up this special issue. We thank our peer reviewers and the authors for their hard work throughout the revision process, as well as the editorial staff at Qualitative Sociology Review. We invite the readership of QSR to consider joining us in Canada for a future Qualitative Analysis Conference, and until then, we hope you enjoy this special issue.

Kind regards, Antony J. Puddephatt Steven Kleinknecht Carrie B. Sanders
Puddephatt, Antony J., Steven Kleinknecht, and Carrie B. Sanders. 2013. “Introduction to the Special Issue. Qualitative Analysis Conference 2012: Cultures of Narrative and Narratives of Culture." Qualitative Sociology Review
9(3):8-11. Retrieved Month, Year (http://www.qualitativesociologyreview.org/ENG/archive_eng.php). 